\title{
Dentoalveolar Distalisation In Class III Skeletal Base Using Buccal Shelf Mini-implants - A Cose Report
}

\author{
Dr Narula Khyati, Dr Shetty Siddarth² \\ 'Private Practitioner, \\ ${ }^{2}$ Professor and Head, Manipal College of Dental Sciences, Mangalore, Karnataka
}

Correspondence: Dr Khyati Narula; Email: orthokhyati@gmail.com

\section{ABSTRACT}

Before the advent of skeletal anchorage distalisation of the lower arch was considered cumbersome. Individual lower molar distalisation followed by retraction into the distalised space created is very time-consuming. Therefore, to reduce the treatment duration lower arch distalisation can be attempted by using buccal shelf screws. Here we present a case of Angle's Class III malocclusion which has been treated effectively with distalisation of lower arch using 2 buccal shelf screws $(2 \times 12 \mathrm{~mm})$ with elastic chains following lower third molars extraction. We achieved full arch distalisation of $3.5 \mathrm{~mm}$ bilaterally in a span of 1.5 months into a class I molar and canine relationship with normal overjet and overbite. Total treatment duration was of 17 months. These results were stable. There were no changes in vertical facial dimensions.

Keywords: buccal shelf implants, class III malocclusion, dentoalveolar distalisation

\section{INTRODUCTION}

Class III malocclusion has a low incidence and thus its prevalence varies among different ethnic groups.1-3 The severity of class III malocclusion and the patient's age are the determining factors in its treatment. Orthognathic surgery is the option for very severe malocclusion on the other hand, orthodontic camouflage can be attempted in mild to moderate cases.4-5 Camouflage in the past has been attempted with various approaches such as: single lower incisor extraction, high pull headgear, molar protraction and class III elastics.4,6-10 Camouflage treatment can be attempted with two approaches: in first approach extraction of teeth is done either lower premolar or lower incisor.9,11 In the second approach mandibular molar distalisation can be attempted.12-15 Orthodontists consider mandibular molar distalisation as one of the difficult movement to be achieved due to further complexities such as distal tipping and rotation of molars. 16 According to Newton's law, the backward push on molars is opposed by forward movement of anteriors thereby exposing anteriors to jiggling forces.17,18 Lower arch distalisation can be carried out by placing TADs either in retromolar region or interdental region.6 The purpose of this article is to describe a novel technique for en masse lower arch distalisation with buccal shelf screws. These screws are made of stainless steel and diameter is of $2 \mathrm{~mm}$, length varies from $10 \mathrm{~mm}$ or $12 \mathrm{~mm}$ and placed in the buccal shelf are of the mandible. As these screws are placed away from the site of distalisation hence, there is no root contact during distalisation as well as immediate traction can be given for distalisation as soon as third molars are extracted. There is no waiting period involved for bone fill for screws placement in extracted third molar site.

\section{CASE REPORT}

\section{Diagnosis}

A 20-year-old male patient reported to the Department of Orthodontics at Manipal College of Dental Sciences, Mangalore with the chief complaint of irregularly placed upper and lower front teeth. On examination, the patient was found to be mesoprosopic and mesocephalic. Mild crowding was present in the anterior region of both arches, the arches were wide. (Figure 1) Molar and canine relation bilaterally were super class I relation by $3 \mathrm{~mm}$. Periodontal conditions were favorable for orthodontic treatment with a fair oral hygiene. The facial pattern was average to horizontal and Wits value of $-6 \mathrm{~mm}$ with ANB of -1 degree. (Figure 2, Table 1)

\section{Treatment Objectives}

The treatment objectives were to achieve Angle's class I molar and canine relation, decrowding in both the arches, an ideal overjet and overbite without altering the vertical facial dimensions. Hence, we planned to extract lower third molars bilaterally and distalise the lower arch into extraction space using buccal shelf screws. 


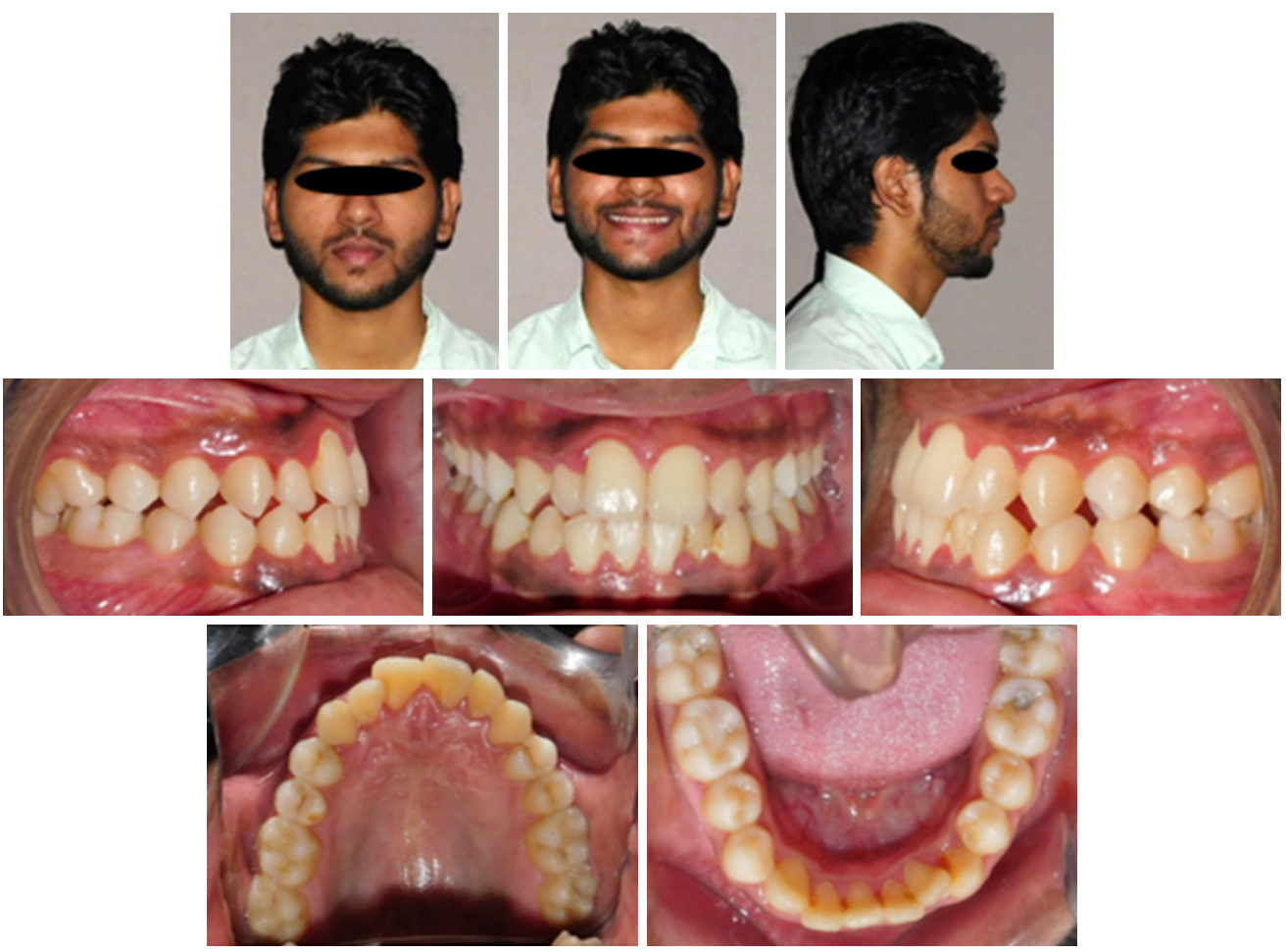

Figure 1: Pre-treatment Photographs

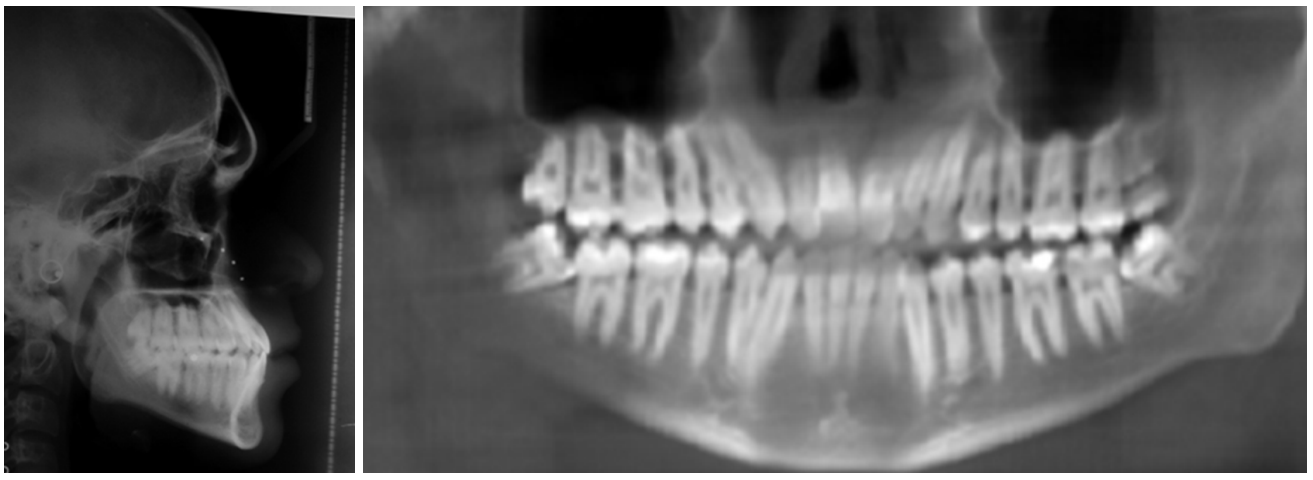

Figure 2: Pre-treatment Radiographs

Table 1: Cephalometric measurements

\begin{tabular}{|c|c|c|c|}
\hline PARAMETERS & NORM & PRE TREATMENT & POST TREATMENT \\
\hline SNA & $83.6 \mathrm{sd} \mathrm{1.9}$ & 89 & 87 \\
\hline SNB & $80 \mathrm{sd} 3.1$ & 90 & 87 \\
\hline ANB & $2.3 \mathrm{sd} 1$ & -1 & -4 \\
\hline Wits & 0 to - & -6 & 91 \\
\hline Co-A & $100.8 \mathrm{sd} \mathrm{3.1}$ & 93 & 131 \\
\hline Co-Gn & $131.6 \mathrm{sd} 4.5$ & 130 & 27 \\
\hline FMA & $22.5 \mathrm{sd} 3.5$ & 23 & 25 \\
\hline SN-Go-Gn & 32 & 20 & $73.4 \%$ \\
\hline Jarabak's ratio(\%) & 62 to 65 & $76.6 \%$ & 121 \\
\hline Gonial angle & $128 \mathrm{sd} 7$ & 124 & 7 \\
\hline Cant of occlusion & 9 & 7 & $31 / 6$ \\
\hline U1 to NA (deg/mm) & $22 / 4$ & $32 / 6$ & $20 / 4$ \\
\hline L1 to NB (deg/mm) & $25 / 4$ & $17 / 3$ & 85 \\
\hline IMPA & 90 & 84 & 131 \\
\hline Interincisal angle & 135 & 1.5 & 3 \\
\hline Overjet (mm) & 2 & 1 & 2.5 \\
\hline Overbite (mm) & 2 & 133 & \\
\hline
\end{tabular}



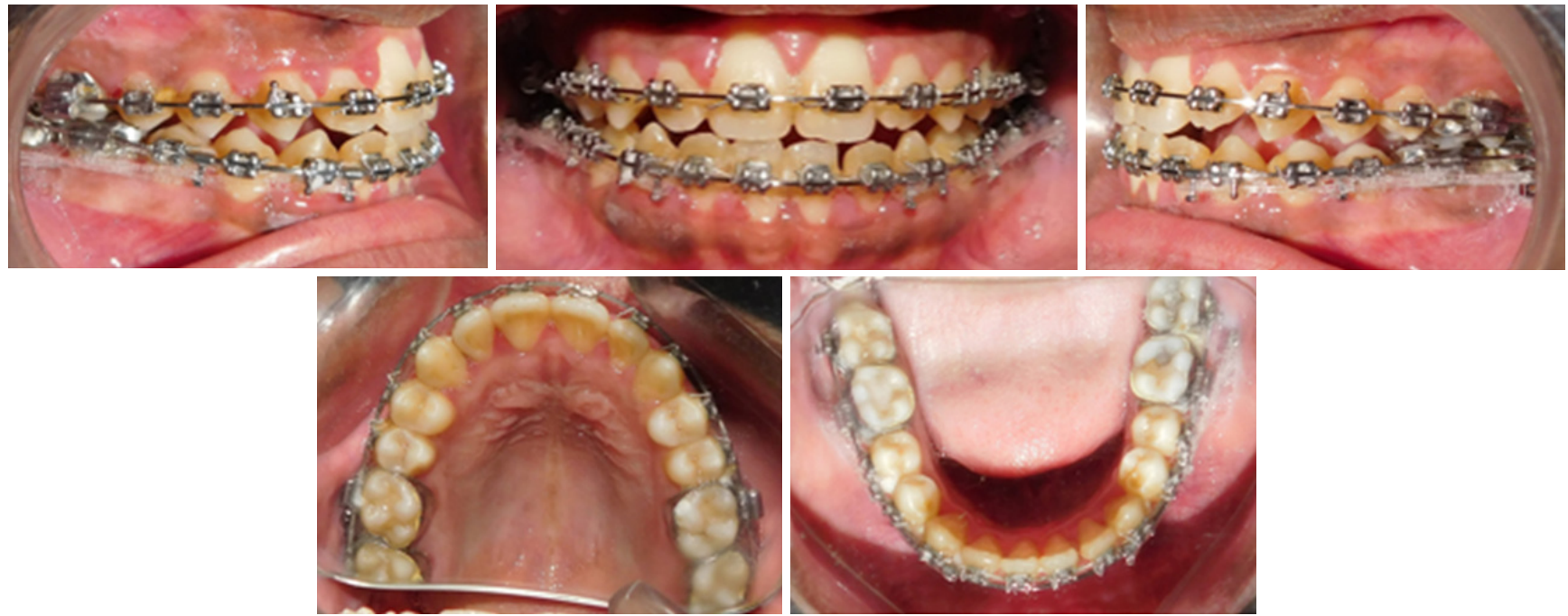

Figure 3: Buccal shelf screws for distalisation

\section{Treatment Progress}

Both upper and lower arches were bonded and banding is done for maxillary first and second molars. Mandibular second molars were banded a week after lower third molar extractions. Roth prescription 0.022 brackets were bonded. Sequenced stage of leveling and aligning was carried and a month before distalisation lower third molars were extracted and lower second molars were banded. 19×25 ss wires were ligated in both arches. Two Bioray stainless steel Buccal Shelf screws of $2 \mathrm{~mm} \times 12 \mathrm{~mm}$ were placed in buccal shelf area between lower first and second molar region. The implants were loaded a week after placement. There were four crimpable hooks placed: two between first and second premolars and two between lateral incisor and canine. Elastic chain was stretched from crimpable hooks to implants giving $60 z$ of force from premolar region and $5 \mathrm{oz}$ from the canine region. (Figure 3)

After achieving the desired distalisation of $3.5 \mathrm{~mm}$ bilaterally in 1.5 months for a class I molar and canine relation the arches were ligated to the implant to prevent any rebound. The results were stable after 3 months of consolidation. Further $17 \times 25$ ss multi-braided archwires were ligated and box elastics were given for one month for settling the occlusion.

Post-treatment СBCT was taken and no thinning of the lingual cortical plate in the anterior region was evident. The total treatment duration was for 17 months and bonded lingual retainers were placed in both arches. Hawley's retainers were delivered for retention. (Figure 4,5)
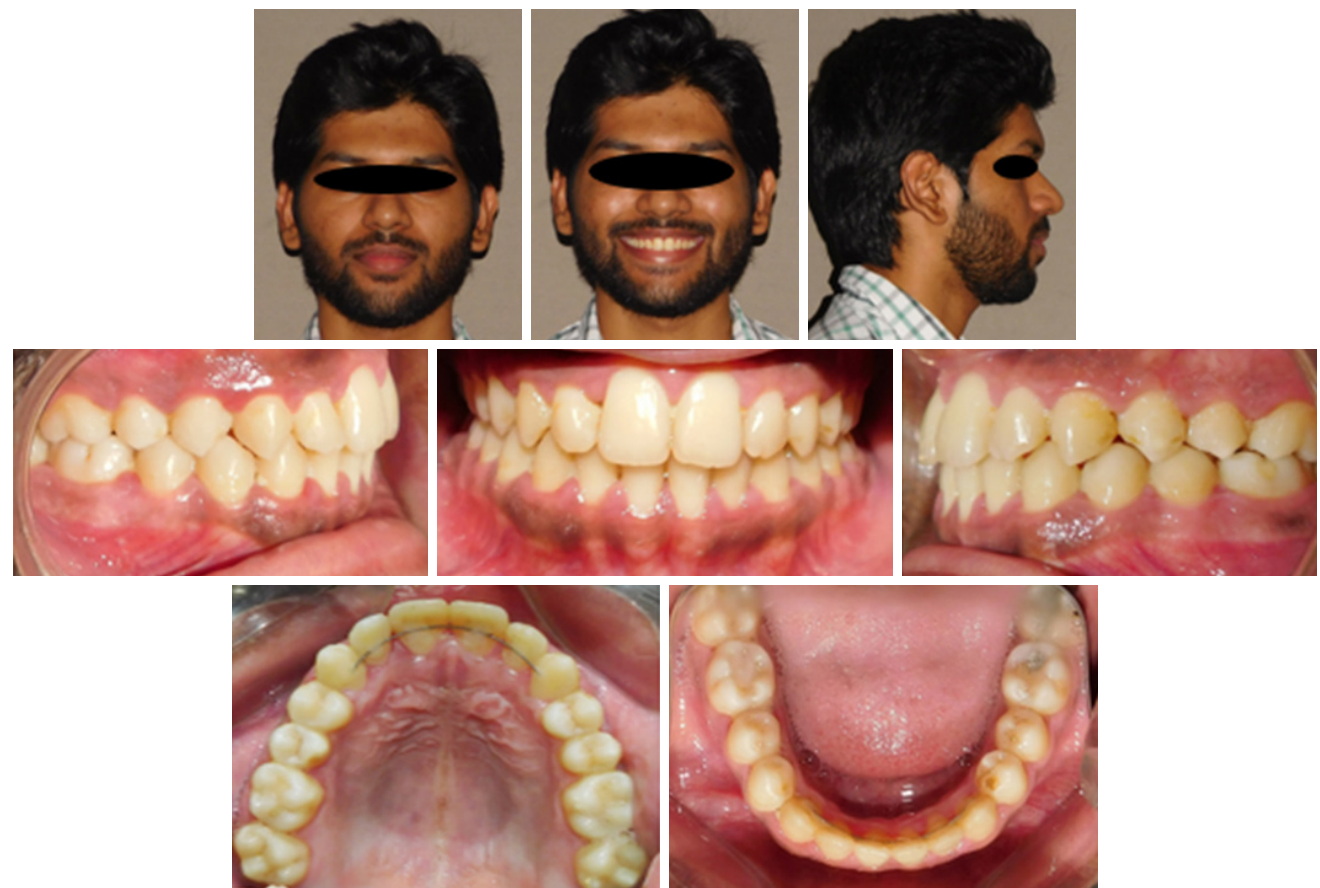

Figure 4: Post-treatment photographs 

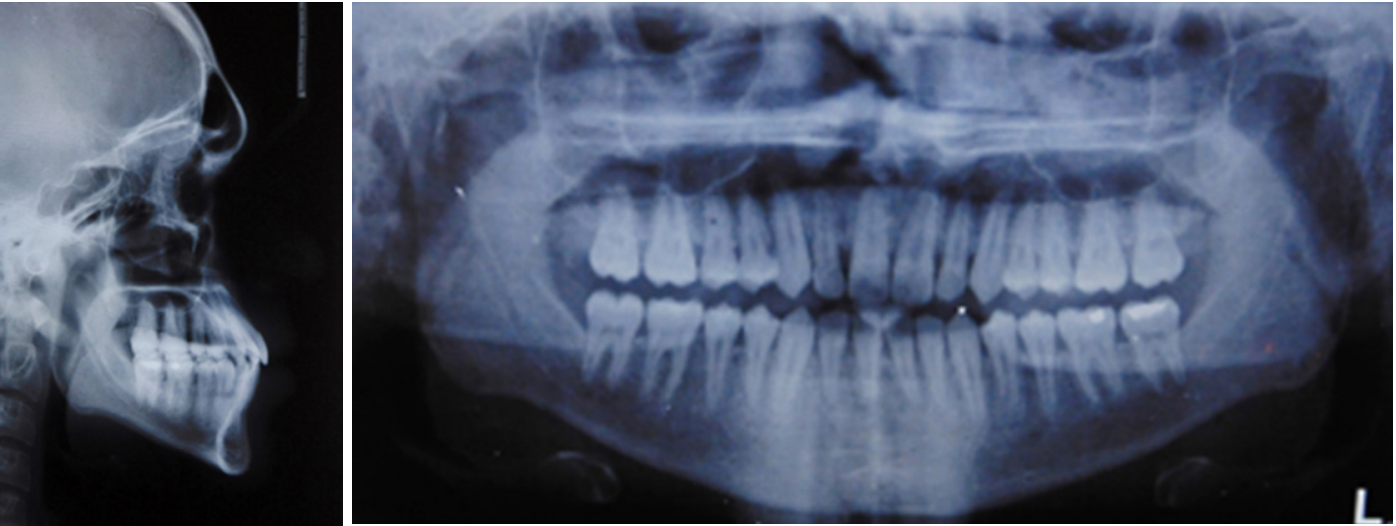

Figure 5: Post-treatment radiographs

\section{DISCUSSION}

This case report demonstrates entire mandibular dentition distalisation with buccal shelf screws and intra arch elastic chain traction. The superclass I molar and the canine relation was converted to Angle's class I occlusion with $3 \mathrm{~mm}$ overjet and $2.5 \mathrm{~mm}$ overbite post-treatment. This technique provides an efficient means to camouflage a borderline class III dentoalveolar malocclusion. Literature review shows that varied techniques such as dental implants and mini-plates have been used for segmental mandibular molar distalisation. ${ }^{19}$ However, both implants and mini plates require complicated surgery for placement. ${ }^{20}$ Miniscrews provide the same resistance against orthodontic load with advantages including No need for osseointegration, minimal anatomic limitations because of smaller available sizes, lower costs, easier placement, and lessen discomfort.

The vertical control is equally important as is a sagittal correction, hence the apical placement of the implant will have a good vertical control but due to soft tissue limitations, the implant cannot be placed more apically near lower second molar region. However, upon superimposition there was no downward mandibular rotation and also no molar extrusion was appreciable. ${ }^{18}$
Two fundamental methods of applying distalising forces are reported in the literature: a tooth-by-tooth distalisation or an en masse distalisation. The latter may be performed by applying a direct reactive force to the first premolars, canines, or to anterior hooks. ${ }^{21}$ In our treatment, we have done en masse distalisation.

Few studies have shown the counter results of placing buccal shelf screws i.e. the lateral component of the force may act to increase the intercanine width and consequently affect the stability of the treatment results. They may also cause rotation of the occlusal plane, increasing the vertical dimension, based on the relationship between the force vector and the center of resistance of the entire arch. ${ }^{22}$ We didn't face any adverse effects of buccal shelf screws in our case. To prevent first and second order side effects rigid wire should be used for distalisation.

\section{CONCLUSION}

The Buccal shelf implants can withstand heavier loads and appear as a viable option for lower full arch distalisation. When compared to retromolar implants there is no waiting period required for bone fill in the third molar region, thus advantageous.

\section{OJN}




\section{REFERENCES}

1. Massler M, Frankel J, Massler M, Frankel J. Prevalence of malocclusion in children aged 14 to 18 years. Am J Orthod. 1951; 37(10):751-68.

2. Haynes S. The prevalence of malocclusion in English school children aged 11-12 years. Trans Eur Orthod Soc. 1970:89-98.

3. Thilander B, Myberg N. The prevalence of malocclusion in Swedish school children. Scand Dent Res. 1973; 81:12-20

4. Saito I, Yamaki M, Hanada K. Nonsurgical treatment of adult open bite using edgewise appliance combined with high-pull headgear and class III elastics. Angle Orthod 2005; 75:277-83.

5. Agarwal S, Shah N, Yadav S, Nanda R. Mandibular arch retraction with retromolar skeletal anchorage in a Class III open-bite patient. J Clin Orthod 2014; 48:775-82.

6. Kuroda S, Tanaka E. Application of temporary anchorage devices for the treatment of adult Class III malocclusions. Semin Orthod 2011 ; 17:91-8.

7. Faerovig E, Zachrisson BU. Effects of mandibular incisor extraction on anterior occlusion in adults with Class III malocclusion and reduced overbite. Am J Orthod Dentofacial Orthop 1999; 115:113-24.

8. Janson G, de Souza JE, Alves Fde A, Andrade P Jr, Nakamura A, de Freitas MR, et al. Extreme dentoalveolar compensation in the treatment of Class III malocclusion. Am J Orthod Dentofacial Orthop 2005; 128:787-94.

9. Moullas AT, Palomo JM, Gass JR, Amberman BD, White J, Gustovich D. Nonsurgical treatment of a patient with a Class III malocclusion. Am J Orthod Dentofacial Orthop 2006;129(4 Suppl): S111-8.

10. Daher W, Caron J, Wechsler M. Nonsurgical treatment of an adult with a class III malocclusion. Am J Orthod Dentofacial Orthop. 2007; 132(2):243-51.

11. Hisano M, Chung C-Ryung J, Soma K. Nonsurgical correction of skeletal class III malocclusion with a lateral shift in an adult. Am J Orthod Dentofacial Orthop. 2007; $131(6): 797-804$.

12. Sakai YC, Kuroda S, Murshid S, Takano-Yamamoto T. Skeletal class III severe open bite treatment using implant anchorage. Angle Orthod. 2008; 78(1):157-66.

13. Chung K-R, Kim S-H, Choo H, Kook Y-A, Cope JB. Distalization of the mandibular dentition with mini-implants to correct a class III malocclusion with a midline deviation. Am J Orthod Dentofacial Orthop. 2010; 137(1):135-46.

14. Mora DR, Oberti G, Ealo M, Baccetti T. Camouflage of moderate class III malocclusions with the extraction of lower second molars and mandibular cervical headgear. Progr Orthod. 2007; 8(2):300-07.

15. Poletti L, Silvera A, Ghislanzoni LH. Dentoalveolar class III treatment using retromolar miniscrew anchorage. Progr Orthod. 2013 14:7.

16. Oh Y-H, Park H-S, Kwon T-G. Treatment effects of micro implant-aided sliding mechanics on distal retraction of posterior teeth. Am J Orthod Dentofacial Orthop. 2011; 139(4):470-81.

17. Park H-S, Lee S-K, Kwon O-W. Group distal movement of teeth using microscrew implant anchorage. Angle Orthod. 2005; 75(4):602-09.

18. Robert WE, Helm FR, Marshall KJ, Gonglo $\square$ RK. Rigid endosseous implant for orthodontic and orthopedic anchorage. Angle Orthod 1989; 59:247-56.

19. Turley PK, Kean C, Schur J, Stefanac J, Gray J, Hennes J, et al. Orthodontic force application to titanium endosseous implants. Angle Orthod 1988; 58:151-62.

20. Oh Y-H, Park H-S, Kwon T-G. Treatment effects of micro implant-aided sliding mechanics on distal retraction of posterior teeth. Am J Orthod Dentofacial Orthop. 2011; 139(4):470-81

21. Sung EH, Kim SJ, Chun YS, Park YC, Yu HS, Lee KJ. The distalization pattern of whole maxillary dentition according to force application points. Korean J Orthod 2015; 45:20-8.

22. Bechtold TE, Kim JW, Choi TH, Park YC, Lee KJ. The distalization pattern of the maxillary arch depending on the number of orthodontic miniscrews. Angle Orthod 2013; 83:266-73. 